\title{
Application of Neural Networks in Predicting the Level of Integration in Supply Chains
}

\author{
Emanuel Guillermo-Muñoz ${ }^{1}$ iD, Neyfe Sablón-CossíoiD, Sebastiana del Monserrate Ruiz-Cedeño ${ }^{3}$ (D), \\ Sonia Emilia Leyva-Ricardo ${ }^{4}$ iD, Yeni Cuétara-Hernández ${ }^{5}$ iD, Erik Orozco-Crespo ${ }^{6}$ iD \\ ${ }^{1}$ Instituto de Ciencias Básicas, Universidad Técnica de Manabi (Ecuador) \\ ${ }^{2}$ Instituto de Posgrado, Universidad Técnica de Manabi (Ecuador) \\ ${ }^{3}$ Facultad de Ciencias Administrativas y Económicas, Universidad Técnica de Manabí (Ecuador) \\ ${ }^{4}$ Facultad de Ciencias de la Ingeniería e Industrias, Universidad Técnica Equinoccial, Sede Santo Domingo (Ecuador) \\ ${ }^{5}$ Universidad Católica de Cuenca (Ecuador) \\ ${ }^{6}$ Investigador del grupo Proserv, Universidad Técnica de Manabi (Ecuador) \\ emanuel.guillo@gmail.com,nsabloncossio@gmail.com,moncitaruiz@gmail.com, \\ sonia.leyva@ute.edu.ec,yeniscue@gmail.com,erikcopo@gmail.com
}

Received: October 2019

Accepted: January 2020

\begin{abstract}
:
Purpose: This investigation is based on the theoretical analysis of the application of neural networks to the design and manage supply chains, along with an empirical approach, this investigation its developed with the prediction of the level of integration in the supply chain through neural networks.
\end{abstract}

Design/methodology/approach: The methodology designed and used for the processing of data was the instruction of a neural network which is used to predict the level of integration in a supply chain. This type of predictive application appears in the literature reviewed on supply chains. This analysis was carried out in a comparative way with the heterogeneous and homogeneous weights of the neuron training.

Findings: The main results of this research focus on predicting the level of integration in the supply chain from the neuronal network. This provides a coached neuron that can be applied in other studies and, therefore, predict the outcome. On the other hand, it is shown that if the weights of the integration level variables are not homogeneous, the procedure presents different results depending on the context in which it is developed.

Research limitations/implications: Among the limitations of the implementation of neural networks it should be noted, the necessary adaptation to the characteristics of the supply chains and the areas of performance of the business organizations under study, in the framework of activities productive or service itself, in addition to analyzing its corporate purpose in relation to the satisfaction of certain needs of the target markets.

Originality/value: The literature shows multiple theoretical sources that refer to studies of neural networks in supply chains, observing the opportunity to apply this technique to predict the level of integration due to its benefits for decision making. The originality of this scientific work lies in the possibility of comparing the historical data of the level of integration and those predicted as a result of the coaching of the neuron with the weights of the heterogeneous and homogeneous variables.

Keywords: neural networks, supply chains, integration processes 


\section{To cite this article:}

Guillermo-Muñoz, E., Sablón-Cossío, N., Ruiz-Cedeño, S.M., Leyva-Ricardo, S.E., Cuétara-Hernández, Y., \& Orozco-Crespo, E. (2020). Application of neural networks in predicting the level of integration in supply chains. Journal of Industrial Engineering and Management, 13(1), 120-132. https://doi.org/10.3926/jiem.3051

\section{Introduction}

The integration of supply chains (ISC) is a required element in the gates of Industry 4.0. These radicates from the interrelation of the processes and internal flows of each company, to the combination of the processes and flows of multiple performers; on the other hand, that these processes are aligned according to the chain's strategy, with the goal of satisfying the customer (Cooper, Lambert \& Pagh, 1997; Al-Doori, 2019). Other performers classify the levels of integration in relation to their complexity (Pires \& Carretero-Díaz, 2007; Sablón-Cossío, Pulido-Rujano, Orozco-Crespo \& Ruíz-Cedeño, 2018): Assignment, Market Negotiations, Association, Cooperation, Coordination and Collaboration.

At the same time, the ISC has two perspectives: vertical and horizontal (Villareal-Solís \& Gómez-Romero, 2009; Chackelson, Errasti, Martinez \& Santos, 2013). In addition, the ISC can be classified as centralized and decentralized (López-Lira, 2007; Wahyuni, Vanany \& Ciptomulyono, 2019). On the other hand, the integration in some studies focuses on a specific variable (Salas-Navarro, Maiguel-Mejía, Acevedo-Chedid, 2017; Breitling, 2019; Cogollo-Flórez \& Correa-Espinal, 2019; Fulconis \& Philipp, 2019), and in others it applies holistically along the chain (Hoseini-Shekarabi, Gharaei, Karimi, 2019; Kumar, Brint, Shi, Upadhyay \& Ruan, 2019; Yu, Zhang \& Huo, 2019).

Based on this need, estimating ISC is a challenge. Where traditional approaches arise as descriptive and inferential analysis (Sablón-Cossío, Pulido-Rujano et al., 2018). Together with management philosophies that focus on collaboration between parts of the supply chain, for example: Supplier-managed inventory (VMI), Customer relationship management (CRM), Efficient consumer response (ECR), Provision and replenishment of collaborative planning (CPFR), (Kazemi \& Zhang 2013).

Based on this neccesity, the ISC estimate is a challenge. Coming from traditional approaches such as descriptive and inferential analysis (Acevedo-Urquiaga, 2013; Sablón-Cossío, Pulido-Rujano et al., 2018). On the other hand, other studies with a renewal approach such as artificial intelligence. For example: the blurry logic for the selection of variables (Bautista-Santos, Martínez-Flores, Fernández-Lambert, Bernabé-Loranca, Sánchez \& Sablón-Cossío, 2015) and qualify the solutions to face the risk in the supply chain networks (Jafarnejad, Momeni, Abdollahi, Safari \& Nakhai-Kamalabadi, 2018), the genetic algorithms (Liu \& Ran 2019), the structural equation modeling for (Sreedevi \& Saranga, 2017) and the neural networks for variable forecasting (Baharmand, 2019). This last perspective is the subject of this article.

The goal of this article is to predict the level of integration in the supply chain through neural networks in two different contexts, the architecture algorithm and the supervised learning algorithm. The importance of this research lies in its methodological contribution, due to obtaining a trained neural network that can predict integration in order to make decisions in different contexts. In addition to the social contribution, which is framed in the possibilities of making early decisions to possible consumer needs.

The particular background of this research work in relation to the technique used is the procedure of training a neural network as defined in (Muñoz, Cedeño, Ruiz \& Cruz, 2019). In this case, a prediction of success or failure of a purchase request from one financial institution to another was made.

\subsection{Applications of Neural Networks in Supply Chains}

The application of neural networks in supply chains has been diverse and towards different variables. Scientific texts related to the subject, are generally searched in three databases: Springer, Taylor and Francis and Elsevier. These identify 55 documents related to the particular issue between the period from 1995 to 2019. 
From these studies, some uses were identified in the: optimization of processes and flows in the chain, the prediction of some of the variables, modeling and simulation, globalization (integration), decision support and risk management as the last characteristic of greater presence. Out of which $22 \%$ refers to the forecast, $20 \%$ to globalization, $16 \%$ model and simulation and support for decisions in equal amounts, $13 \%$ to optimization and risk management as detailed in Figure 1.

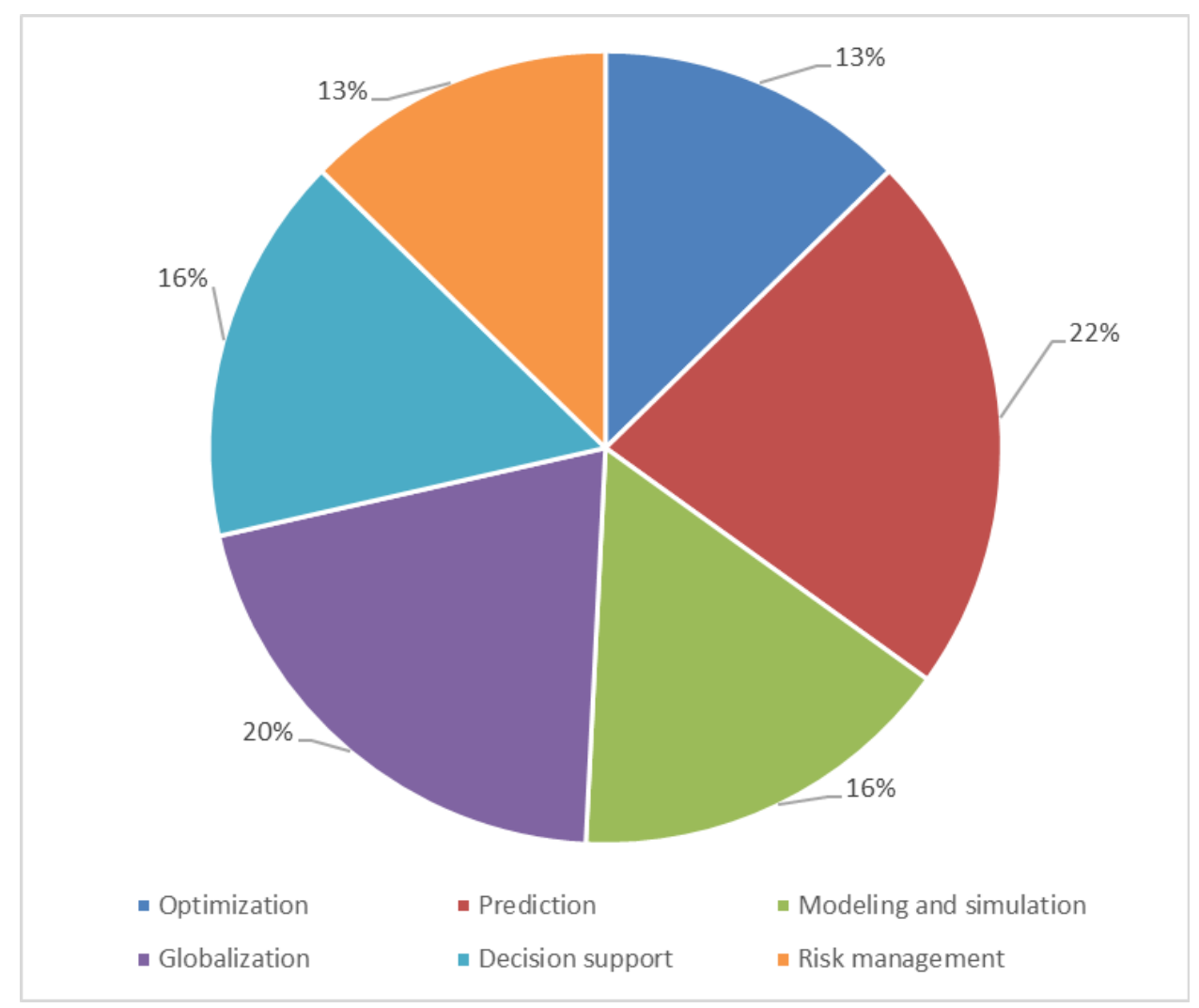

Figure 1. Analysis of the use of neural networks in supply chains

Out of these, globalization is directly related to this research. Of this percentage $(16 \%)$ refer to studies on how variables that favor integration are predicted or related (Leung, 1995; Chiu \& Lin, 2004; Minis \& Ampazis, 2006; Li, Lai \& Nie, 2007; Lichun \& Cai, 2008; Jeeva \& Guo, 2010; Lee, Jung \& Nie, 2010; Singh \& Benyoucef, 2010; Bousqaoui, Said \& Tikito, 2017; Yang, 2017; Kokkinos, Exadactylos, Vafidis \& Hatziioannou, 2018; Liu \& Ran, 2019). In the study by Chiu and Lin (2004), neural networks are used for the evaluation of collaborative planning in supply chains. The latter focuses on the modeling of the mitigation of errors between objectives and clients, as a mechanism for collaboration between the actors in the supply chain.

\subsection{Preliminary Research Work Related to the Subject Under Study}

The study of the level of integration in the supply chain has several approaches according to the specialized literature. Despite this, this article uses the methodology for evaluating the level of integration of Sablón-Cossío, Cárdenas-Uribe, Pérez-Quintana, Bravo-Sánchez and Manjarez-Fuente (2018). This algorithm has been used in supply chains of various countries, products and scopes as described in Table 1.

This methodology begins with the selection of the work group in each actor. These are based on the experience of the staff and the influence of their knowledge in decision making. The degree of importance is assigned to each variable by the working group, using the Hierarchical Analytical Method. The checklist of 91 items of Sablón-Cossío, Pulido Rujano et al. (2018) to each of the actors in the chain. It is analyzed through a descriptive statistical study, where the weight of each variable is multiplied by the results of the corresponding items. 


\begin{tabular}{|c|c|c|c|c|}
\hline No. & Objects of study & Classification & Application & Developing \\
\hline 1 & Supply chain of tomato puree in Matanzas, Cuba & Product & Total & Medium \\
\hline 2 & Cadena comercial CIMEX, SA, Cuba & Service & Total & High \\
\hline 3 & Matanzas medical supply chain, Cuba & Service & Total & High \\
\hline 4 & Milk supply chain in Matanzas, Cuba & Product & Total & High \\
\hline 5 & Panela supply chain in Puyo, Ecuador & Product & Partial & Low \\
\hline 6 & Milk supply chain in Puyo, Ecuador & Product & Partial & Medium \\
\hline 7 & Juice supply chain of Veracruz, Mexico & Product & Partial & Medium \\
\hline 8 & Chocolate supply chain of the Ecuadorian Amazon & Product & Partial & Low \\
\hline 9 & Ilex Guayusa supply chain, Ecuador & Product & Initial & Low \\
\hline 10 & Textile supply chain of northern Ecuador & Product & Partial & Low \\
\hline 11 & Coconut supply chain in the province of Manabí, Ecuador & Product & Partial & Low \\
\hline 12 & Corn supply chain in the province of Manabí, Ecuador & Product & Partial & Low \\
\hline 13 & Rice supply chain in the province of Manabí, Ecuador & Product & Partial & Low \\
\hline 14 & Supply chain of construction materials, Cuba & Product & Total & Low \\
\hline 15 & $\begin{array}{l}\text { Coffee supply chain with the focal company located in Calceta, } \\
\text { Ecuador }\end{array}$ & Product & Partial & Low \\
\hline 16 & $\begin{array}{l}\text { Supply chain in the Agroexportadora and marketer Junipertree } \\
\text { Cía LTDA }\end{array}$ & Product & Partial & Low \\
\hline 17 & Supply chain Andean Hardware of Colombia & Product & Partial & Low \\
\hline
\end{tabular}

Table 1. Studies of supply chains of various countries, products and scopes (Elaborated from the results and research articles of Sablón and collaborators from 2013 to 2019).

A set of variables under study has been identified as detailed below: Strategy (D1), Information (D2), Planning (D3), Purchases (D4), Inventory (D5), Transportation (D6) and Collaborative Performance (D7). These are broken down into items that are evaluated with a Likert scale from 1 to 5 for items measured in ordinal scale, where the value 1 corresponded with the criterion of very low and 5 with that of very high. Finally, the level of integration of the chain was determined by the following expression:

$$
N I_{c s}=\sum_{n=1}^{7} P_{n} * M o_{n}
$$

Where:

$\mathrm{P}_{n}$ : Specific weight of importance granted by experts for dimension $\mathrm{n}$.

$\mathrm{NI}_{\sigma}$ : Level of chain integration.

$M o_{n}$ : Mode calculated for each En, $\mathrm{m}$ and for each $C D_{n}$.

$i\{I=1,2 \ldots k\}$ : company $i$ analyzed, where $\mathrm{k}$ represents the size of the selected sample (number of companies).

$D_{n}\{n=1,2 \ldots 7\}$ : Dimension $n$ analyzed from the set of dimensions.

$E_{n}, m\{m=1,2 \ldots l\}: m$ items measured within the $\mathrm{n}$ dimension, where $l$ represents the total number of elements measured within each $\mathrm{n}$ dimension.

$C D n$ : Ordinal variable that evaluates the categorized score for dimension $n$.

$C M_{i}$ : Conglomerate of membership of the company $i$.

$C S_{i}$ : Total collaboration score obtained for the company $i$.

$M o$ : Mode calculated for each $E_{n}, \mathrm{~m}$ and for each $C D_{n}$.

From the level of integration of the chain, the strategies and joint objectives of the supply chain in relation to the object of investigation are identified. Due to this, the need arises to identify a prospect of this level, in order to anticipate possible market changes for this purpose, the use of neural networks is proposed. 


\section{Materials and Methods}

The training methodology of a neural network of Muñoz et. al (2019) to predict the level of integration in the supply chain. In these algorithms are used for the construction of a neural network: the architecture algorithm and the supervised learning algorithm.

\subsection{Architecture, Multilayer Neural Network}

- Number of neurons in the input layer: The number of neurons is determined by the number of independent variables.

- Number of hidden layer neurons: It is determined by the pyramidal formula, to approximate the number of neurons in the hidden layer.

$$
h=\sqrt{i \cdot o}
$$

Where:

$b($ hidden $)=$ Number of neurons in the hidden layer.

$i$ (imput) $=$ Number of input neurons.

$o$ (output) $=$ Number of output neurons.

$$
h=\sqrt{i \cdot o}=\sqrt{7 * 1}=2,64 \cong 3
$$

To determine the initial number of neurons in the hidden layer, Equation (2) is used, which results in the value of three neurons. From this number, a series of tests were carried out establishing the value of ten neurons avoiding a mismatch or over-adjustment in the learning of the neural network. From the number of neurons in the output layer, whose role is to predict or estimate a numerical value, the last layer is made up of a neuron.

\subsection{Supervised Learning Algorithm}

Neural network learning takes place through the backpropagation learning algorithm, which consists of five steps:

\section{a) Initialization}

As there is no prior information, the weights and balances of each connection are initialized with random values between 0 and 1 .

Formula for the net value of the output in each neuron.

$$
v=\sum_{i=0}^{i=q}\left(\omega_{i} \cdot i_{i}+b\right)
$$

Where:

$v=$ Net worth.

$i_{i}=$ Number of input neurons, of the input variables.

$\omega_{i}=$ Weights associated with each connection of the neural network.

$b=$ Neural netwok balance.

Sigmoid function, establishes whether the output signal of each neuron is exciter or inhibitor. It is responsible for calculating the level of the activation state by generating an exciting signal (very high values) or inhibitory (very small values) from the net input of each neuron.

$$
f(v)=\frac{1}{1+e^{-v}}
$$

Activation function evaluated with the net value. 


$$
a=f\left(\sum_{i=0}^{i=q}\left(\omega_{i} \cdot i_{i}+b\right)\right)
$$

Where:

$a=$ Activation function.

To simplify calculations in the following applies the first derivative to the activation function:

$$
f^{\prime}(v)=f(v) \cdot(1-f(v))
$$

\section{b) Presentation of the training sample}

Choose an input pattern of the data $X^{(k)}$ to be analyzed. Each variable will enter a neuron in the input layer.

\section{c) Forward phase}

Propagate the signal forward through the network, calculating the net inputs and activation function of each perceptron in the neural network.

Calculate $\delta_{i}^{L}$. The learning error in the resulting layer $y_{i}^{L}$, which is the difference between the observed and expected values.

$$
\delta_{i}^{L}=a^{\prime}\left(m_{i}^{L}\right)\left[d_{i}^{\mu}-y_{i}^{L}\right]
$$

\section{Where:}

$\delta_{i}^{L}=$ Propagation of the signal forward.

$y_{i}^{L}=$ Learning error in the resulting layer.

$m_{i}^{L}=$ Input to the network in the ith unit in the L-th layer.

$a^{\prime}=$ Derived from the activation function.

$d_{i}^{\mu}=$ Observed values.

\section{d) Backward phase}

The learning error marks the most appropriate way to update the weights that will produce a satisfactory response at the end of the training. The deltas for the preceding layers are calculated by propagating the errors backwards.

$$
\delta_{i}^{L}=a^{\prime}\left(h_{i}^{l}\right) \Sigma_{i} w_{i j}^{l+1} \delta_{j}^{l+1}
$$

For $1=(\mathrm{L}-1)$ layers.

$\Sigma_{i} w_{i j}^{l+1} \delta_{j}^{l+1}=$ Total sum of the resulting error.

The modification of each weight is made using Function 8.

$$
\Delta w_{j i}^{l}=n \delta_{i}^{l} y_{j}^{l-1}
$$

The learning method that is the descending gradient is the variation that occurs over time of the value of the weights, spreading the error from the final layer to the input layer. Where $\mathrm{n}$ is the learning factor, which determines the speed with which the neural network learns. The learning factor is the learning speed of the network, through trial and error it must always be between 0.4 and 1 , because if it is very high the value will make the progress of the training faster and therefore may not produce a convergence.

$$
w_{j i}^{l}=w_{j i}^{l}+\Delta w_{j i}^{l}
$$


Equation 10 calculates the new weight value by adding the increase $\Delta \mathrm{w}$ to the current weight value.

\section{e) Iteration}

Steps 3 and 4 are repeated with the training sample until the algorithm adjusts the weights of the network to minimize the mean square error of the learning error until a decrease of less than $10^{-6}$

The application of this procedure is carried out in the Rstudio IDE (Integrated Development Environment) program of Neuralnet (2019).

Both methodologies are applied to a supply chain in the context of Ecuador. First the Integration Level (NI) is calculated by the traditional method and then this result is predicted through the neural networks. These two results are correlated and the prediction error is determined. This study is carried out both for different and equal levels of importance and these results are compared.

\section{Results}

The procedure for forecasting neural networks is applied, with two specifications when the weight is homogeneous and heterogeneous, based on the established process of the algorithm making the comparisons of the errors.

\section{Case study 1: Textile supply chain in Northern Ecuador}

The chain under study has five links and 109 actors, is classified as: suppliers of inputs, suppliers of raw materials, processing center, clothing, distribution and customers. Within the marketing there are two classifications: that of wholesalers who sell their products in large volumes and supply to other actors, on the other hand, we find retailers (which are those that come directly to the customer and are dedicated to selling in small quantities). This may be at the national level and also at the international level, but there are few international sales due to the low collaboration between the actors in the chain.

Input suppliers supply machinery and raw materials, there is only one actor within the area under study. The fabric is the main raw material that is used for the manufacture of shirts, quality and easy access depend on the success of the actors who are dedicated to the transformation of this. These can be industrial fabrics or knitted fabrics. Within this link there are also the manufacture and threads, these are used by manufacturers for clothing.

From the identification of the actors, the checklist for the evaluation of the level of integration was applied to them. On the other hand, the values of the application of the checklist and the analysis of the seven dimensions with the heterogeneous and homogeneous weights are described respectively, as detailed in Table 2 and 3. Both with seven input variables and one output variable.

The architecture of the network, an input layer is identified is composed of seven neurons for each covariate, the hidden layer has ten neurons, and the output layer, one because it is predictable.

A random sample of $70 \%$ of the database is taken, thereby performing the neuron training. From the data of each of the variables pass to each input neuron. Weights and balances of each connection are made plus a balance (Equation 3). With the characteristic that weights and balances are used between 0 and 1 . The activation function is continued (Equation 4). This calculation is performed on each neuron in the neural network. In the case, that the values as a result of the activation function generates signals of very high or very low levels. This encourages the definition of the importance of each neuron. With the goal of simplifying the calculations, the first derivative of the function used is applied, and together to promote the propagation of the signal forward (importance of the variable). This is applied progressively until the last network layer, resulting layer.

The learning error of the neural network that establishes the difference between the real value of the variable and the estimated one is calculated. If that square error is different from 0 , or 10-6, the backprogapation process begins, which is backward learning. Continue to update the weights of the connections back until you reach the input layer, and start again with the fordward process. As a result of the processing of the starting information, trained models are shown in Figures 2 and 3. 


\begin{tabular}{|c|c|c|c|c|c|c|c|}
\hline Strategy & Information & Planning & Purchases & Inventory & Transport & Performance & IL \\
\hline 3.23124684 & 1.4 & 2.4 & 2.3 & 1.78260246 & 2.4 & 2.7 & 2.53 \\
\hline 2.48396071 & 1.6 & 3.1 & 2.3 & 1 & 1.2 & 3.2 & 2.38 \\
\hline 1.29154967 & 2.1 & 1.4 & 3.2 & 1.90365394 & 2.6 & 2.9 & 2.87 \\
\hline 2.97819065 & 3.7 & 3.8 & 3.8 & 3.77635005 & 3.5 & 4.0 & 3.66 \\
\hline 3.55198718 & 2.4 & 3.9 & 1.4 & 1.58489319 & 2.3 & 1.3 & 2.66 \\
\hline 4.1434962 & 4.0 & 4.3 & 2.2 & 3.31445402 & 3.6 & 4.6 & 3.84 \\
\hline 3.95054315 & 2.7 & 5.0 & 2.7 & 3.51948203 & 2.7 & 2.9 & 3.63 \\
\hline 3.70349885 & 2.0 & 3.1 & 2.8 & 1.93318204 & 2.6 & 4.3 & 3.02 \\
\hline 3.46500297 & 2.5 & 3.7 & 3.5 & 2.49146188 & 3.3 & 3.3 & 3.47 \\
\hline 3.66735939 & 2.8 & 5.0 & 3.9 & 3.75848008 & 3.1 & 4.6 & 3.92 \\
\hline 1 & 1.0 & 1.0 & 1.0 & 1 & 1.0 & 1.0 & 2.95 \\
\hline 3.35599673 & 2.3 & 3.3 & 3.2 & 2.49146188 & 1.7 & 3.6 & 3.05 \\
\hline 2.72158 & 2.9 & 3.3 & 2.8 & 2.70192008 & 2.6 & 4.3 & 3.19 \\
\hline 2.93578259 & 2.0 & 3.8 & 2.0 & 3.06388706 & 2.9 & 4.6 & 2.94 \\
\hline 3.35599673 & 1.9 & 3.3 & 2.2 & 3.72791927 & 2.5 & 3.6 & 3.36 \\
\hline 3.04491964 & 3.7 & 4.0 & 2.7 & 3.12913464 & 2.2 & 2.7 & 3.47 \\
\hline 3.78647901 & 3.9 & 4.0 & 2.8 & 3.06388706 & 2.2 & 5.0 & 2.47 \\
\hline 3.86396754 & 1.2 & 3.6 & 2.5 & 2.04767251 & 1.1 & 2.2 & 3.03 \\
\hline 3.51505574 & 1.3 & 4.1 & 3.7 & 3.36586544 & 2.0 & 3.6 & 3.22 \\
\hline 3.49476004 & 3.0 & 3.3 & 2.5 & 3.17767152 & 2.4 & 4.3 & 3.83 \\
\hline 4.38547668 & 3.2 & 3.4 & 3.7 & 3.10369115 & 3.9 & 4.3 & 4.30 \\
\hline
\end{tabular}

Table 2. Input and response variables with homogeneous weights

\begin{tabular}{|c|c|c|c|c|c|c|c|}
\hline Strategy & aformation & Planning & Purchases & Inventory & Transport & Performance & IL \\
\hline 3.23124684 & 1.3642616 & 2.39429671 & 2.3164482 & 78260246 & 2.36873784 & 2.71441762 & .31028733 \\
\hline 2.48396071 & 5223896 & 12090331 & 2.2616199 & 1 & 1.15775367 & 3.1748021 & 2.11734704 \\
\hline 1.29154967 & 2.14610795 & 616 & 3.15939443 & 1.90365394 & 2.6265278 & 2.92401774 & 2.20221616 \\
\hline 2.97819065 & 3.66801617 & 3.77176819 & 3.77352978 & 3.77635005 & 3.4646424 & 4 & 3.63321389 \\
\hline 3.55198718 & 2.41369038 & 3.92432815 & 1.42510267 & 1.58489319 & 2.27771211 & 1.25992105 & 2.34823353 \\
\hline 4.1434962 & 3.97635364 & 4.31417399 & 2.22313072 & 3.31445402 & 3.63263979 & 4.64158883 & 3.74940531 \\
\hline 3.95054315 & 2.7065999 & 5 & 2.74899919 & 3.51948203 & 2.71666654 & 2.92401774 & 3.36661551 \\
\hline 3.70349885 & 1.95797309 & 3.13016916 & 2.79315787 & 1.93318204 & 2.550849 & 4.30886938 & 2.91109991 \\
\hline 3.46500297 & 2.53917695 & 3.72241944 & 3.54225252 & 2.49146188 & 3.3081847 & 3.30192725 & 3.1957751 \\
\hline 3.6673 & 2.7689921 & 5 & 3.87890064 & 3.75848008 & 3.06969341 & 8883 & 3.82643064 \\
\hline 1 & 1 & 1 & 1 & 1 & 1 & 1 & 1 \\
\hline 3.35599673 & 2.27597015 & 3.3417448 & 3.22892588 & 2.49146188 & 1.73835044 & 3.5568933 & 2.85562045 \\
\hline 2.72158 & 2.91295063 & 3.33655972 & 2.76532176 & 2.70192008 & 2.55568309 & 4.30886938 & 3.04326924 \\
\hline 2.93578259 & 2 & 3.81637959 & 2.00820826 & 3.06388706 & 2.90814574 & 4.64158883 & 3.05342744 \\
\hline 3.35599673 & 1.8858841 & 3.30975092 & 2.2341949 & 3.72791927 & 2.50713518 & 3.5568933 & 2.93968206 \\
\hline 3.04491964 & 3.71140042 & 3.95611499 & 2.71330584 & 3.12913464 & 2.21880473 & 2.71441762 & 3.06972827 \\
\hline 3.78647901 & 3.93597934 & 3.9881593 & 2.81319792 & 3.06388706 & 2.23444455 & 5 & 3.54602103 \\
\hline 3.86396754 & 1.18920712 & 3.55655882 & 2.51372012 & 2.04767251 & 1.09682498 & 2.15443469 & 2.34605511 \\
\hline
\end{tabular}




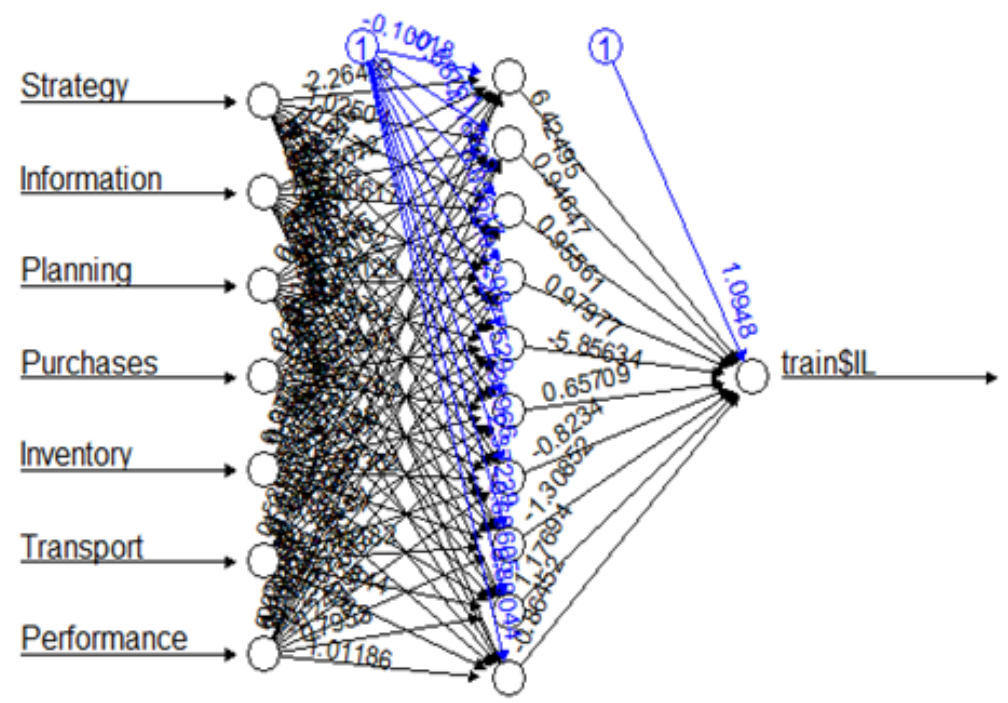

Figure 2. Multilayer perceptron neuronal network model of heterogeneous weights

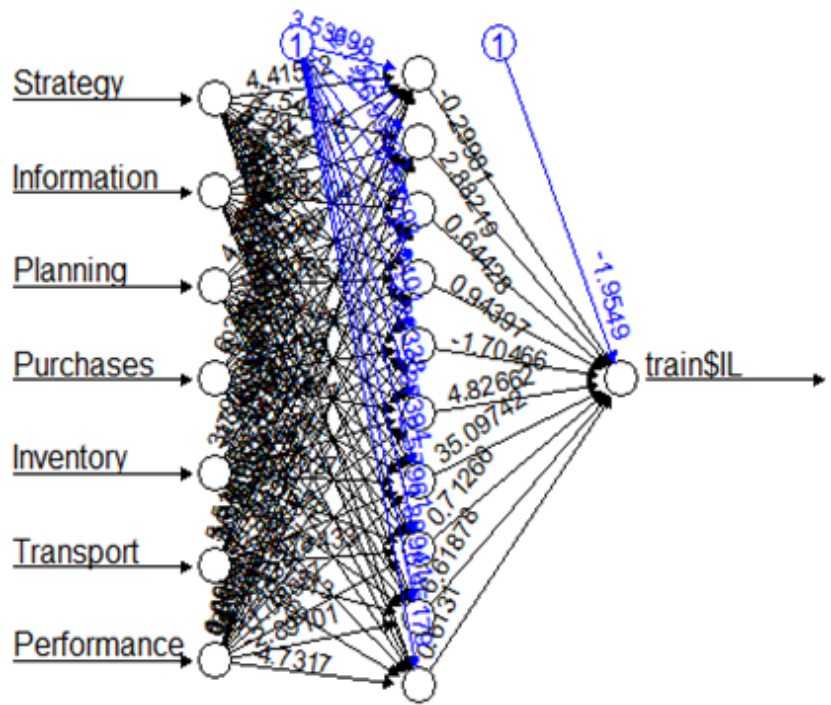

Figure 3. Multilayer perceptron neural network model of homogeneous weights

Actual and estimated values, corresponding to $30 \%$ of the data used to test the model, there are negative estimators, these are preliminary results, the ranges must be adjusted. The execution time of the learning algorithm of neurons with heterogeneous weights is 6.31 seconds and with homogeneous weights is 0.75 seconds. This demonstrates the performance of the second in relation to the predetermined time. The estimated results of the resulting variable with heterogeneous and homogeneous weights (Table 4), demonstrates the use of the neural network model makes better estimates with the homogeneous weights of the input variables in the initial layer.

With the objective of evaluating the model of the neural network, $30 \%$ of the data are used, which were not part of the training of the network, on the other hand, the model is applied and the real and estimated values are estimated with the process explained previously. These estimators are compared with the real values and the Spearman correlation coefficient is calculated, in order to establish that the data have similar values and closest to 1 or -1 . In relation to the correlation, the results of the chain with heterogeneous weights are low with a value of 0.2251772 . On the other hand, the correlation factor of the variables with homogeneous weights is high 0.9754289 as shown in Figure 4. 


\begin{tabular}{|c|c|c|c|}
\hline \multicolumn{2}{|c|}{ Heterogeneous weights } & \multicolumn{2}{|c|}{ Homogeneous weights } \\
\hline IL & Estimated & IL & Estimated \\
\hline 2.6250000 & 2.6937514 & 2.942462 & 2.957075 \\
\hline 3.6562500 & 2.6275137 & 2.509014 & 2.651073 \\
\hline 1.9843750 & 5.6137751 & 2.834999 & 2.808690 \\
\hline 4.0937500 & 3.3212067 & 1.766715 & 1.118399 \\
\hline 2.7656250 & 3.0884369 & 1.490729 & 1.426434 \\
\hline 3.0156250 & 3.1321704 & 2.968960 & 3.017301 \\
\hline 3.0625000 & 2.0731637 & 3.195775 & 3.184163 \\
\hline 3.3125000 & 4.1835068 & 2.945607 & 2.931571 \\
\hline 2.2698410 & 3.3170986 & 3.049569 & 3.130698 \\
\hline 1.5625000 & 0.5456455 & 3.180565 & 3.180129 \\
\hline 3.7343750 & 3.0765270 & 2.891579 & 2.849573 \\
\hline 3.4687500 & 3.2268433 & 3.053427 & 2.973534 \\
\hline 3.4843750 & 4.6990598 & 3.546021 & 3.559277 \\
\hline 3.3437500 & 2.5776652 & 2.608398 & 2.712160 \\
\hline 3.4843750 & 2.0437828 & 2.117347 & 2.255752 \\
\hline 3.2812500 & 3.2525889 & 3.409900 & 3.425798 \\
\hline 3.0781250 & 3.3719487 & 2.754579 & 2.851331 \\
\hline 3.0000000 & 3.0962231 & 2.420099 & 2.424787 \\
\hline
\end{tabular}

Table 4. Resulting variable NI with heterogeneous and homogeneous weights
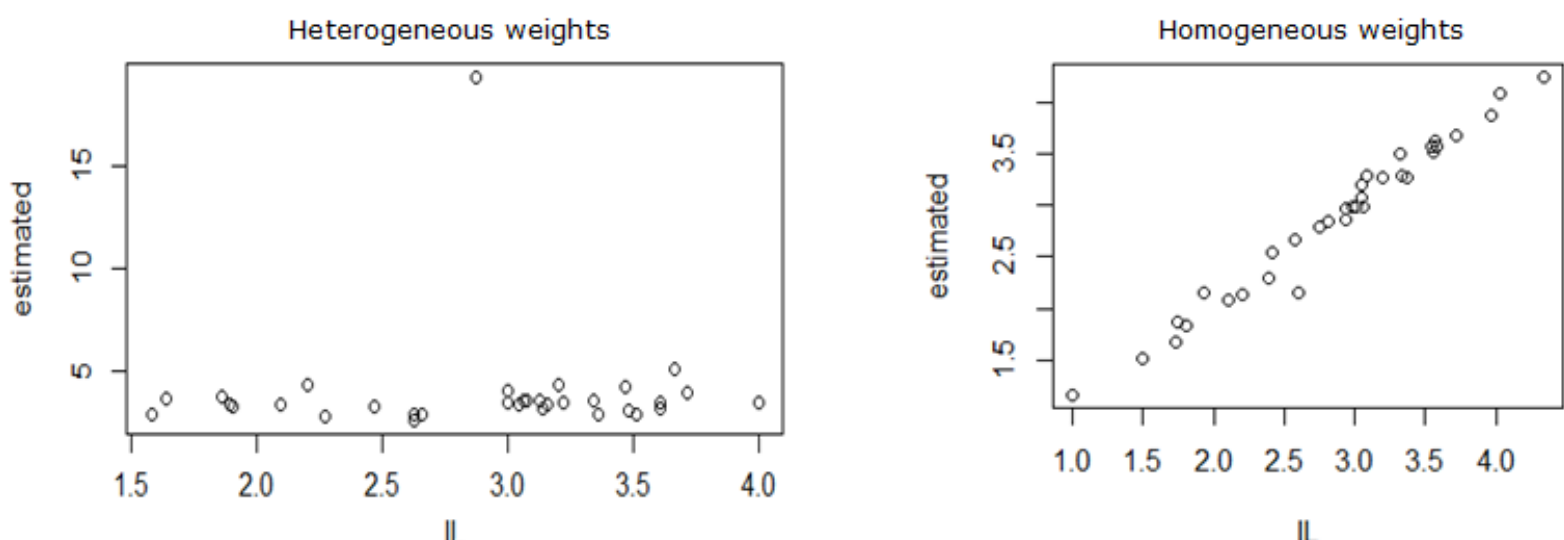

Figure 4. Comparison of the correlation graphs of the estimated response variable of networks trained with heterogeneous and homogeneous weights.

It is concluded that the application of neural networks can be used with homogeneous weights to estimate the level of integration in the supply chain. This encourages decision-making only with the input variables of the integration level. This analysis is convergent based on the variables and their weights respectively.

\section{Discussion}

The study of the integration in the supply chains presents different perspectives: from the management of the flow and the processes from the supplier to the final customer, the integration variables and their optimization (customer service, costs, cycles, demand, inventory), the collaboration between the actors and their processes, information 
management and support media (internet and applications), risk prevention (ISO 31000), sustainability and sustainability, agility and traceability over the chain. Despite this variety, there are gaps aimed at the application of technologies and tools that allow the foundation of decision-making, as is the case of the textile supply chain in Northern Ecuador. The incorporation of neural networks allows the identification based on a prospective analysis of possible market changes, and adopting the action plan required to mitigate the effects of the behavior of exogenous variables in relation to the problem under study.

\subsection{Conclusions}

At present, the use of a technique for forecasting the integration of the supply chain is essential when anticipating market changes. It is an indispensable element to minimize the risks and the achievement of the principles of Industry 4.0. In this research, the application of neural networks in the prediction of the level of integration in the chains of the textile industry in northern Ecuador was presented. The study concluded that the use of neural networks is evident for the problem of forecasting integration in the study supply chain with homogeneous weights, which makes it possible to make decisions on equal terms. In addition, a set of techniques that shaped the neural network methodology were used, which demonstrates the robustness of the algorithm and its possible application to different problems. The results obtained show the application in the textile sector in Ecuador. In future research, it is proposed to compare the results of neural networks in different supply chains of study interest.

\section{Declaration of Conflicting Interests}

The authors declared no potential conflicts of interest with respect to the research, authorship, and/or publication of this article.

\section{Funding}

The authors received no financial support for the research, authorship, and/or publication of this article.

\section{References}

Acevedo-Urquiaga, A.J. (2013). Modelo de Gestion Colaborativa del Flujo Logístico. Thesis presented in option to the scientific degree of Doctor of Technical Sciences. Instituto Superior Politécnico "José Antonio Echeverría".

Al-Doori, J.A. (2019). The impact of supply chain collaboration on performance in automotive industry: Empirical evidence. Journal of Industrial Engineering and Management, 12(2), 13. https://doi.org/10.3926/jiem.2835

Baharmand, H. (2019). Forecasting transportation delays and capacity constraints in humanitarian supply chains by neural networks.

Bautista-Santos, H., Martínez-Flores, J.L., Fernández-Lambert, G., Bernabé-Loranca, M. B., Sánchez, F., \& Sablón-Cossío, N. (2015). Integration model of collaborative supply chain. DYNA Medellin, 82(193), 145-154. https://doi.org/10.15446/dyna.v82n193.47370

Bousqaoui, H., Said, A., \& Tikito, K. (2017). Machine learning applications in supply chains: An emphasis on neural network. applications. https://doi.org/10.1109/CloudTech.2017.8284722

Breitling, A. (2019). Möglichkeitsdichtung-Wirklichkeitssinn: Paul Ricoeurs hermeneutisches Denken der Geschicbte. Wilhelm Fink Verlag.

Chackelson, C., Errasti, A., Martinez, S., \& Santos, J. (2013). Supply strategy configuration in fragmented production systems: An empirical study. Journal of Industrial Engineering and Management, 6(3), 742-750. https://doi.org/10.3926/jiem.554

Chiu, M., \& Lin, G. (2004). Collaborative supply chain planning using the artificial neural network approach. Journal of Manufacturing Technology Management, 15, 787-796. https://doi.org/10.1108/17410380410565375 
Cogollo-Flórez, J.M., \& Correa-Espinal, A.A. (2019). Analytical modeling of supply chain quality management coordination and integration: A literature review. Quality Management Journal, 26(2), 72-83.

https://doi.org/10.1080/10686967.2019.1580553

Cooper, M.C., Lambert, D. M., \& Pagh, J.D. (1997). Supply Chain Management: More than a New Name for Logistics'. The International Journal of Logistics Management. 8(1), 1-14. https://doi.org/10.1108/09574099710805556

Fulconis, F., \& Philipp, B. (2019). La supply chain face aux défis de la livraison e-commerce: entre intégration et flexibilité, quelles solutions packaging? Logistique \& Management, 27(2), 132-147.

https://doi.org/10.1080/12507970.2018.1546127

Hoseini-Shekarabi, S.A., Gharaei, A., \& Karimi, M. (2019). Modelling and optimal lot-sizing of integrated multi-level multi-wholesaler supply chains under the shortage and limited warehouse space: generalised outer approximation. International Journal of Systems Science: Operations \& Logistics, 6(3), 237-257. https://doi.org/10.1080/23302674.2018.1435835

Jafarnejad, A., Momeni, M., Abdollahi, B., Safari, H., \& Nakhai-Kamalabadi, I. (2018). Planning for disruptions in supply chain networks. Uncertain Supply Chain Management, 6, 135-148. https://doi.org/10.5267/j.uscm.2017.8.003

Jeeva, A., \& Guo, W. (2010). Supply Chain Flexibility Assessment by Multivariate Regression and Neural Networks. Lecture Notes in Electrical Engineering, 67. https://doi.org/10.1007/978-3-642-12990-2_98

Kazemi, Y., \& Zhang, J. (2013). Optimal decisions and comparison of VMI and CPFR under price-sensitive uncertain demand. Journal of Industrial Engineering and Management, 6(2), 547-567. https://doi.org/10.1007/978-3-64212990-2_98

Kokkinos, K., Exadactylos, A., Vafidis, D., \& Hatziioannou, M. (2018). Efficient traceability of aquatic products on the cold supply chain management via Io T and artificial neural networks.

Kumar, N., Brint, A., Shi, E., Upadhyay, A., \& Ruan, X. (2019). Integrating sustainable supply chain practices with operational performance: an exploratory study of Chinese SMEs. Production Planning \& Control, 30(5-6), 464-478. https://doi.org/10.1080/09537287.2018.1501816

Lee, Y.H., W. Jung, W., \& Won-Cho, D. (2010). A framework for managing supply-chain flexibility using a neural network. International Journal of Logistics Systems and Management, 6. https://doi.org/10.1504/IJLSM.2010.032945

Leung, H.C. (1995). Neural networks in supply chain management.

Li, W., Lai, M.Y., \& Nie, K. (2007). Performance Evaluation of Cold Chain Based on BP Neural Network. https://doi.org/10.1061/40932(246)164

Lichun, T., \& Cai, X. (2008). RBF Neural Network for the Priority of Buyer Order in Supply Chain. International Conference on Wireless Communications, Networking and Mobile Computing, WiCOM 2008.

Liu, L., \& Ran, W. (2019). Research on supply chain partner selection method based on BP neural network. Neural Computing and Applications. https://doi.org/10.1007/s00521-019-04136-6

López-Lira, N. (2007). Elementos de integración de microempresas comerciales en el oriente del Estado de México en los primeros años del siglo XXI. Contaduría y administración, 221, 109-136.

Minis, I., \& Ampazis, N. (2006). Applications of Neural Networks in Supply Chain Management, 589-607. https://doi.org/10.4018/978-1-59140-984-7.ch039

Muñoz, E.G., Cedeño, F.O., Ruiz, S.M., \& Cruz, J.C. (2019). Aplicación de redes neuronales para predecir el éxito de la compra de deuda a una entidad financiera. Revista ESPACIOS, 40(20).

Neuralnet (2019). Rstudio de IDE (Integrated Development Environment).

Pires, S.R.I., \& Carretero-Díaz, L.E. (2007). Gestión de la Cadena de Suministros. Madrid, España. McGraw-Hill. 
Sablón-Cossío, N., Cárdenas-Uribe, M.B., Pérez-Quintana, M., Bravo-Sánchez, L.R., \& Manjarez-Fuente, N. (2018). Milk agroalimentary chain sustainable development strategy in the conditions of the Ecuadorian Amazon region. Proceedings of the International Conference on Industrial Engineering and Operations Management. Bandung, Indonesia. March 6-8.

Sablón-Cossío, N., Pulido-Rujano, A. Orozco-Crespo, E., \& Ruíz-Cedeño, M. (2018). Integration in supply chains. Case study in Colombia and Ecuador. Proceedings of the International Conference on Industrial Engineering and Operations Management.

Salas-Navarro, K., Maiguel-Mejía, H., \& Acevedo-Chedid, J. (2017). Inventory Management Methodology to determine the levels of integration and collaboration in supply chain. Ingeniare. Revista cbilena de ingeniería, 25(2): 326-337. https://doi.org/10.4067/S0718-33052017000200326

Singh, R.K., \& Benyoucef, L. (2010). Improved decision neural network-based approach for supply chain coordination. 7th CIRP International Conference on Intelligent Computation in Manufacturing Engineering - CIRP ICME. Naples, Italy.

Sreedevi, R., \& Saranga, H (2017). Uncertainty and supply chain risk: The moderating role of supply chain flexibility in risk mitigation. International Journal of Production Economics, 193, 332-342. https://doi.org/10.1016/j.ijpe.2017.07.024

Villareal-Solís, F., \& Gómez-Romero, J. (2009). La integración en las pequeñas y medianas empresas fabricantes de muebles en la ciudad de Durango. Contaduría y Administración, 227.

Wahyuni, H., Vanany, I., \& Ciptomulyono, U (2019). Food safety and halal food in the supply chain: Review and bibliometric analysis. Journal of Industrial Engineering and Management, 12(2), 373-391. https://doi.org/10.3926/jiem.2803

Yang, W. (2017). Supply chain management of agricultural products based on competitive neural network and SVM. Boletin Tecnico/Tecbnical Bulletin, 55, 492-499.

Yu, Y., Zhang, M., \& Huo, B. (2019). The impact of supply chain quality integration on green supply chain management and environmental performance. Total Quality Management \& Business Excellence, 30(9-10), 1110-1125. https://doi.org/10.1080/14783363.2017.1356684

Journal of Industrial Engineering and Management, 2020 (www.jiem.org)

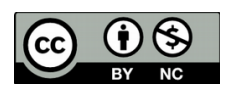

Article's contents are provided on an Attribution-Non Commercial 4.0 Creative commons International License. Readers are allowed to copy, distribute and communicate article's contents, provided the author's and Journal of Industrial Engineering and Management's names are included. It must not be used for commercial purposes. To see the complete license contents, please visit https://creativecommons.org/licenses/by-nc/4.0/. 